\title{
Las redes sociales como herramientas de Relaciones Públicas de las instituciones europeas
}

\author{
Recibido: 02 de diciembre de 2010 \\ Aceptado: 27 de julio de 2011 \\ Publicado: 31 de octubre de 2011
}

\author{
Xosé Baamonde Silva \\ xbaamonde@uvigo.es \\ Universidad de Vigo (España)
}

Resumen: La Internet es el ágora digital donde todos pueden participar. Las instituciones europeas pueden utilizar las redes sociales como herramientas de diálogo con los ciudadanos para lograr su implicación y compromiso con el proceso de construcción europea. Esta investigación se centra en el análisis de los espacios en la Internet de las principales entidades de la UE para comprobar si están utilizando las nuevas potencialidades tecnológicas para contactarse directamente con la ciudadanía o todavía mantienen una especial atención hacia los medios de comunicación como intermediarios para hacer llegar sus mensajes a la opinión pública.

Palabras clave: Relaciones Públicas, redes sociales, Web 2.0, gobierno abierto, construcción europea.

\begin{abstract}
Internet is the digital agora in where that all can participate. The European institutions can use the social networks like tools of dialogue with the citizens to attain his implication and commitment with the process of European construction. This investigation analyses the spaces in Internet of the main entities of the EU to check if they are using the new technological potentialities to converse directly with the citizenship or still keep a special attention to the media like intermediaries to transmit their messages to the public opinion.
\end{abstract}

Key words: Public Relations, Social Networks, Web 2.0, Open Government, European Construction. 


\section{Introducción}

La participación ciudadana en los asuntos públicos ha ido creciendo hasta el punto de que los poderes tradicionales se han visto obligados a compartir, o por lo menos justificar, las decisiones sobre el futuro de la sociedad. Las administraciones precisan que su gestión busca el consenso de la ciudadanía para llevar a buen puerto sus políticas. Para ello, tradicionalmente, las organizaciones e instituciones recurrían a los medios de comunicación como catalizadores de la opinión pública en la sociedad y con la manifiesta voluntad de incrementar su visibilidad. Con la irrupción de las nuevas posibilidades que ofrecen Internet, la $\mathrm{Web} 2.0 \mathrm{y}$, especialmente, las redes sociales, se produce un nuevo escenario.

Una sociedad política es una comunidad de actores, de ciudadanos que actúan conjuntamente y no una simple agregación de individuos que viven unos junto a los otros y se reparten un bien que se supone común. Los gobernantes intentan trasladar su visión y sus propuestas a la sociedad. Para ello, tradicionalmente utilizaban a los medios de comunicación, que sincronizan los temas y catalizan la atención de todos y contribuyen a establecer un espacio común de debate, discusión y legitimación.

La aparición de Internet está provocando cambios sustanciales en la forma en que los ciudadanos se relacionan (o pueden y quieren relacionarse) con sus gobiernos, ya que permite una interacción directa y una comunicación bidireccional entre gobernantes y gobernados. Las nuevas herramientas de la Web 2.0 y su evolución abren la posibilidad para que los ciudadanos realicen una labor mucho más activa en la vida política y social, exigiendo transparencia en la acción de gobierno y participación en la toma de decisiones en los asuntos que les atañen. Los poderes públicos tienen el deber y la responsabilidad de establecer cauces de comunicación y conversación permanentes y facilitar una mayor implicación de la ciudadanía en la gestión pública.

La aplicación de las Relaciones Públicas, por parte de las instituciones europeas, puede contribuir a la construcción de estos espacios de encuentro con los ciudadanos. Para Solano (1999: 98) las RR. PP. surgen "cuando una determinada sociedad adquiere plena conciencia de que existe una necesidad de intercomunicación social y, al mismo tiempo, de que el modelo presuntamente idóneo para satisfacerla exige unos conocimientos o aptitudes y un esfuerzo susceptibles de constituir una profesión autónoma”.

Una aportación de gran interés es la realizada por los teóricos norteamericanos Grunig y Hunt (2000), quienes definen las Relaciones Públicas como la gestión de la comunicación entre una organización y sus públicos. Los autores identifican cuatro modelos de la práctica de esta disciplina en dos criterios: el propósito de la comunicación ("persuasión" versus "entendimiento mutuo") y la naturaleza de la comunicación ("unidireccional" versus "bidireccional").

Siguiendo a Xifra (2008) podemos explicar estos modelos. El primero ("agente de prensa") describe el uso de la comunicación unidireccional centrada únicamente en una cobertura mediática positiva. El objetivo primario de los profesionales que practican este modelo es persuadir a los públicos para que se comporten de la manera en que la organización 
quiere que actúen. En este modelo, los relacionistas actúan como "profesionales de la desinformación". Así, difunden información (a menudo incompleta y deformada) a favor de sus clientes. Se trata de un modelo de comunicación unidireccional, de la organización hacia los públicos. Históricamente, el "agente de prensa" apareció en el periodo 18501900. No obstante, aún sigue vigente en algunas regiones.

El segundo modelo (“información pública”) emplea la comunicación unidireccional para transmitir mensajes veraces de interés público. Aquí, el fin de las Relaciones Públicas es la difusión de información, no necesariamente con finalidad persuasiva. El profesional actúa, o debería actuar, como si de un periodista integrado a la organización se tratara, es decir, aplicando los principios de la información de actualidad, con la función de transmitir al público (interno o externo) información sobre la misma. Si bien la comunicación también es unidireccional, la información transmitida es mucho más exhaustiva. El modelo de “información pública" surgió a principios del siglo XX y todavía está vigente, especialmente en la comunicación de los poderes públicos y de las organizaciones sin ánimo de lucro.

La finalidad del tercer modelo ("asimétrico bidireccional") es la "persuasión científica" (Grunig y Hunt, 2000), es decir, de aquellos profesionales que practican las Relaciones Públicas asimétricas bidireccionales, los cuales utilizan los métodos y técnicas de las Ciencias Sociales para estudiar las actitudes y comportamientos de los públicos, con el objetivo de que estos acepten el punto de vista de la organización y se comporten de manera que secunden sus decisiones ("asimetría favorable a la organización"). La comunicación es bidireccional: fluye hacia el público y desde el público (retroalimentación). La asimetría se infiere del hecho de que los efectos de las Relaciones Públicas están desequilibrados a favor de la organización. En otras palabras, la organización no modifica su comportamiento, sino que procura modificar las actitudes y las conductas del público. Si bien apareció a partir de 1920, el auge de este modelo ha sido continuo desde entonces, hasta el punto de ser el modelo más practicado actualmente.

El modelo "simétrico bidireccional" ha supuesto uno de los ejes vertebradores de teoría contemporánea de las Relaciones Públicas. Si bien constituye el ideal normativo por excelencia dentro de esta disciplina, ha generado muchas críticas, revisiones y adaptaciones desde su formulación. Los profesionales de las Relaciones Públicas que lo practican actúan como mediadores entre la organización y los públicos de su entorno. El fin es el entendimiento mutuo entre ambas partes. La teoría y los métodos empleados son los de la comunicación más que los persuasivos. La comunicación simétrica bidireccional se traduce en un diálogo que debería llevar, en palabras de Grunig y Hunt (2000), a que la organización y el público modificasen sus actitudes y comportamientos después de la ejecución del programa de Relaciones Públicas. Esta sería la situación resultante ideal del ejercicio de esta especialidad profesional.

El modelo simétrico bidireccional se empezó a practicar en la década de 1960, pero no se consolidó hasta finales del siglo XX. Hoy, con la llegada de la Web 2.0 y la utilización de las redes sociales, los Estados y las instituciones tienen una excelente oportunidad para desarrollarlo con eficacia y dialogar en un plano de igualdad con los ciudadanos.

Esta investigación tiene por objetivos comprobar si realmente se están adoptando las medidas necesarias para explotar las posibilidades de las redes sociales como herramientas 
al servicio de Relaciones Públicas por parte de las instituciones de la Unión Europea (UE) y si estas están desarrollando un modelo simétrico bidireccional que contribuya a una mayor identificación de los europeos con sus órganos políticos de gobierno. Ello permitiría profundizar en la democracia y mejorar las relaciones con las administraciones públicas a través de los medios sociales.

La metodología del estudio se centra en un análisis de contenido de los sitios web de las principales instituciones de la UE, con el objetivo de comprobar cómo están aprovechando esta oportunidad para lograr una mayor participación ciudadana en el proyecto de construcción europea.

La hipótesis que se pretende comprobar es si los organismos de la Unión Europea están fomentado un verdadero diálogo interactivo y bidireccional que implique a los nuevos ciudadanos digitales, más críticos y con mayores posibilidades de comprometerse con el bien común.

\section{Las Relaciones Públicas en el proceso de construcción europea}

Si bien la práctica de esta especialidad comunicacional tiene larga data (hay autores que determinan su origen en las civilizaciones de la Antigüedad), sea en acciones que buscaron incrementar la notoriedad de personajes, colectivos o entidades; estas carecieron de metodología, de un contexto sociopolítico verdaderamente democrático, de desarrollo tecnológico suficiente y de medios de comunicación sofisticados. Por ello, consideramos que las Relaciones Públicas surgen como actividad regular a finales del siglo XIX y lo hacen como necesidad de la nueva sociedad industrial que comenzaba a consolidarse.

De acuerdo con Castillo (2010) se pueden catalogar cinco periodos fundamentales en su evolución:

- Desde finales del siglo XIX a 1914, con algunos ejemplos primigenios de acciones de Relaciones Públicas que iban configurando su deber ser.

- De 1914 a 1918, fuertemente impregnada con las técnicas de propaganda, que se aplicaron en la Primera Guerra Mundial y, sobre todo, en los Estados Unidos con la gran estrategia de comunicación para convencer a su población de que era necesario entrar en la guerra.

- De 1919 a 1929, que arrastra las consecuencias de los excesos del periodo anterior y se produce una cierta aversión a la potencialidad de la comunicación, pero al mismo tiempo, las Relaciones Públicas comienzan a insertarse como disciplina universitaria y tiene lugar el primer libro de la especialidad.

- De 1929 hasta 1945, en la que se potencia la actividad de las Relaciones Públicas dirigidas a las grandes masas, debido a la época de crisis económica de 1929 y el esfuerzo comunicativo, entre otros, que supuso la Segunda Guerra Mundial.

- A partir de 1945 y hasta nuestros días. A partir de década del cincuenta se universaliza en Occidente, debido principalmente a la extraordinaria influencia norteamericana en los campos político, social y económico. 
Las Relaciones Públicas suponían en el pasado (y suponen en el presente) un esfuerzo deliberado, planeado y sostenido para establecer y mantener la compresión mutua entre las administraciones y sus públicos (Noguero, 1995: 191). Así, los objetivos a alcanzar deben ser mantener al ciudadano debidamente informado; que sea bien atendido (y así lo perciba) cada vez que se dirija a la administración; que se dé respuesta de forma rápida y eficaz a sus demandas y problemas; que se potencie la participación ciudadana. En definitiva, que el individuo tenga la seguridad de que están a su servicio.

En palabras de Castillo y Almansa (2008), las administraciones públicas son instituciones que basan su existencia en la gestión de los intereses de los ciudadanos. Esa comunicación administración/ciudadano se ha realizado por medios tradicionales, pero con la llegada de las tecnologías de la información, estos procesos han ganado interactividad, sobre todo en la década del noventa gracias al uso de la Internet.

Con la llegada de la Internet a las administraciones públicas, en los últimos años se ha llevado a cabo un proceso de transformación hacia la mejora de los servicios prestados al ciudadano, así como la apertura a nuevos canales que facilitan la comunicación institucional. En ese sentido, las redes sociales han abierto de forma exponencial un gran abanico de posibilidades para el diálogo con los ciudadanos.

La actual crisis económica ha situado a la UE, por enésima vez, ante un momento decisivo de su historia. Ahora, más que nunca, es preciso profundizar en la transmisión de los valores europeístas: colaboración y cooperación entre los distintos pueblos de Europa; alentando la unidad y la construcción de un proyecto común; al mismo tiempo que se conserva la diversidad y, sobre todo, garantizando que las tomas de decisiones se realicen de acuerdo con los intereses de los ciudadanos europeos.

La pertenencia a la Unión Europea supone una nueva dimensión para la ciudadanía, pues formamos parte de una comunidad más amplia que nos vincula a instancias democráticas supranacionales y es necesario que los valores para esta convivencia democrática europea sean reconocidos, comprendidos y apoyados por los ciudadanos de los diversos países miembros. Lamentablemente, las instituciones democráticas de la UE y los políticos profesionales que las dirigen, no son percibidas como fuentes legítimas de decisiones que representen la voluntad popular. La integración ha avanzado pero no al ritmo deseado. Una adecuada utilización de las Relaciones Públicas a través de las redes sociales puede contribuir a acelerar este proceso.

Aunque las instituciones comunitarias han facilitado grandes cantidades de información, a través de los medios, el ciudadano medio europeo sigue sin comprender la complejidad institucional de la Unión Europea y su política. Esta situación contribuye al verdadero problema: la falta de identidad con la realidad europea. La UE es percibida como una entidad abstracta, con beneficios y perjuicios difusos. Ese déficit de sentimiento europeo produce el desencanto y la desafectación de los ciudadanos hacia las instituciones y dirigentes de la Unión Europea. Ante este marco, urge tomar medidas para que los ciudadanos comprendan las ventajas que ofrece la integración europea y así mejorar sus aspiraciones y su vida en general (Cabezuelo, 2005). 
Rubio (2010) señala la necesidad de una comunicación activa con los ciudadanos. La comunicación de los Estados con sus ciudadanos ha estado dirigida tradicionalmente hacia los medios de comunicación, de una manera unidireccional y centralizada. Ahora compete ir más allá, para convertirse en una información adaptada en función de los intereses de cada uno, con cierto grado de personalización y abierta al diálogo.

El ciudadano ha dejado de ser el sujeto paciente de las políticas públicas. A través de Internet y de la web social, es el individuo quien puede tomar el poder, organizarse y transmitir sus reivindicaciones. Asimismo, los gobiernos pueden cumplir con su deber de transparencia, estableciendo canales abiertos de información, colaboración, participación y servicio. El objetivo es establecer canales de comunicación directa con los ciudadanos, para que estos puedan recibir personalmente la información y puedan expresar su opinión o solicitar una respuesta. Esto se revertirá en una mayor implicación de los ciudadanos, la adhesión de estos a un programa o a la elaboración de políticas públicas.

\section{Las Relaciones Públicas, el gobierno abierto y la rendición de cuentas}

La búsqueda de una dinámica social creativa e innovadora, que afronte con éxito los retos inmediatos, conlleva el desarrollo de nuevas herramientas y parámetros necesarios para evaluar la actividad de unas instituciones públicas cada vez más exigentes y competitivas en la utilización eficiente de sus recursos. De esta manera, se hace ineludible mejorar el estudio del sector público y de las administraciones. Esta mejora pasa por la optimización de las estructuras de gobierno y por la rendición de cuentas, para la que, a su vez, es indispensable una eficaz comunicación entre gobernantes y gobernados. La evaluación sobre la percepción de la misma en los diferentes canales pasa, por tanto, a ser un objetivo inmediato.

El concepto de "gobierno abierto" hace referencia, en esencia, a una evolución del sistema democrático de convivencia y valores basada en el establecimiento de mecanismos para la transparencia de los gobiernos, así como de espacios permanentes de colaboración y participación de los ciudadanos más allá del ejercicio de derecho de sufragio cada cuatro años. Hablamos, pues, de saltar desde nuestro viejo modelo de democracia representativa a un modelo de democracia "conversacional" y abierta, aprovechando las posibilidades que proporcionan las nuevas tecnologías a los ciudadanos de participar en los procesos de toma de decisiones de los gobiernos. Un "gobierno abierto" es aquel que entabla una constante conversación con los ciudadanos, a fin de oír lo que ellos dicen y solicitan; que toma decisiones basadas en sus necesidades y preferencias; que facilita la colaboración de los ciudadanos y funcionarios en el desarrollo de los servicios que presta y que comunica todo lo que decide y hace de forma abierta y transparente. (Calderón y Lorenzo, 2011: 11).

En este sentido, es preciso recordar las palabras de Barack Obama (2011), en el Memorando para los jefes de los departamentos ejecutivos y agencias: "Mi administración se compromete a crear un nivel sin precedentes de apertura en el Gobierno. Vamos a trabajar juntos para asegurar la confianza del público y establecer un sistema de transparencia, participación pública y colaboración. La apertura será fortalecer nuestra democracia y promover la eficiencia y la eficacia en el Gobierno". En julio de 2011, el primer mandatario estadounidense dio un paso más al responder, desde la Casa Blanca, las preguntas enviadas por los usuarios de Twitter (Pereda, 2011). 
En esta línea podemos situar el concepto de "buen gobierno", que comprende las tradiciones, instituciones y procesos que determinan el ejercicio del poder, la participación ciudadana y la toma de decisiones de acuerdo con el interés general. Para ello, es necesaria la existencia previa de instituciones democráticas de calidad y de prácticas asociadas al buen gobierno de las mismas, a través de los principios de transparencia, participación y rendición de cuentas (Nonel, 2002:11).

Es preciso, por tanto, impulsar una participación más activa de la sociedad en el desarrollo de las políticas públicas y, sobre todo, en la implementación de las mismas. Hay que favorecer principios que permitan una sociedad más abierta, más participativa y más responsable de sus decisiones; eficaz en sus propuestas y actuaciones; y coherente en sus políticas y acciones. Las bases de toda rendición de cuentas están en el desarrollo de una serie de principios básicos: a) la conducta ética y su traducción en un compartimiento regulado por determinados códigos; b) unos sistemas de información que suministren datos entendibles, asequibles y transparentes, que permitan a los ciudadanos identificar los beneficios sociales que produce la actuación política; y c) como condición básica, la voluntad política de llevar a cabo el desarrollo de estos principios que permitan liderar un cambio en la gestión pública y en la elaboración de las políticas públicas para favorecer las innovaciones (Nonel, 2002: 14).

Cuestión importante en toda rendición de cuentas es el papel que juega la sociedad civil. Es deseable conseguir que se implique en este proceso. Para ello es necesario facilitar el camino elaborando una información asequible y entendible; comprometiéndola con el proceso de difusión de la misma a través de su tejido asociativo, de la participación de los medios de información que puedan difundirla y por medio de un programa de Relaciones Públicas que permita un diálogo permanente con los ciudadanos.

La preocupación constante por lograr gobiernos incrementalmente públicos, como consecuencia de la institucionalización de la participación responsable de los ciudadanos, constituye un reto asumido y compartido por la propia sociedad, en donde contar con información suficiente y oportuna se convierte en un requisito sin el cual difícilmente se podría remontar el desinterés de los ciudadanos por participar. Esta circunstancia representa un invaluable instrumento para tornar más pública la relación entre gobernantes y gobernados, siempre y cuando se constituya como parte integral de un proceso que nos oriente a encarar colectivamente, con un sentido de equidad, la impostergable solución de los ingentes problemas de la pobreza y la desigualdad en la que se encuentra la gran mayoría de los habitantes del planeta y que representan la principal amenaza para la viabilidad y futuro de la democracia (León y Ramírez, 2009: 286).

Cada vez son más los autores (Grasa, 2005: 88) que hablan de "gobernanza", aludiendo a un conjunto de mecanismos, procesos, instituciones e incluso valores compartidos mediante los cuales ciudadanos y grupos sociales articulan sus intereses, median sus diferencias y, finalmente, hacen posible el ejercicio de sus derechos y obligaciones legales. La gobernanza, por ende, es un prerrequisito del buen gobierno, una condición necesaria aunque no suficiente. 
En esencia, el concepto de "gobernanza" tiene un campo semántico mayor que el de "Gobierno": incluye al Estado y a las administraciones públicas, pero también al sector privado con finalidad lucrativa (las empresas, las fuerzas del mercado) y al sector privado sin finalidades lucrativas (el llamado "tercer sector", la sociedad civil). La gobernanza implica, por tanto, la interacción entre las instituciones propias del Gobierno (a menudo muy formalizadas y normativizadas) y las instituciones no formales propias de los otros dos sectores altamente informales.

Bajo el término "buen Gobierno" se agrupan aquellos principios, actitudes, conductas y actuaciones de los distintos Gobiernos y organizaciones públicas que permiten implicar más a los ciudadanos en el devenir de la sociedad (Nonel, 2002: 15). La calidad de las intervenciones públicas depende, por tanto, de la calidad de las instituciones democráticas y del buen gobierno de las mismas a través de los principios de transparencia, participación y rendición de cuentas (accountability). Esta supone el requerimiento a una organización, tanto pública como privada, para explicar a la sociedad sus acciones y aceptar consecuentemente la responsabilidad de las mismas. Se trata de favorecer una mayor responsabilidad entre todas las partes, mediante la mejora de los mecanismos de consulta y de diálogo para reforzar la legitimidad de las políticas públicas. Los instrumentos principales son la provisión de información sobre las políticas y las acciones de las diferentes instituciones y organizaciones; y la creación y el estímulo de oportunidades para la consulta y la participación activa de los ciudadanos en la formación y en la elaboración de las políticas públicas.

En una democracia sana hay que esperar que el buen Gobierno requiera una relación constructiva entre el Estado, el gobierno y las organizaciones públicas y privadas; que se establezcan sistemas de rendición de cuentas en estas diferentes esferas para entender y valorar mejor sus relaciones. En definitiva, perseguir una sociedad más transparente y predispuesta a la rendición de cuentas de sus acciones y actuaciones, permite estimular una participación más activa de sus ciudadanos, de su tejido asociativo y, a la vez, tenderá los puentes necesarios para que las instituciones y organizaciones se acerquen a la ciudadanía.

La rendición de cuentas involucra, por tanto, el derecho a recibir información y la obligación correspondiente de divulgar todos los datos necesarios. Pero también implica el derecho a recibir una explicación y el deber correspondiente de justificar el ejercicio del poder (Schendler, 2004: 13). La comunicación y los vínculos entre gobernantes y gobernados permite identificar percepciones y prioridades de los gobernados y los temas de relevancia social. La comunicación ayuda a crear las bases de una cultura de la transparencia y del diálogo que disminuya el riesgo de corrupción; contar con información para tomar decisiones informadas y consensuadas; o definir los mecanismos de transparencia para la información.

Se ha mostrado que la transparencia en sus diferentes formas cobra cada vez más importancia para fortalecer la democracia y para ofrecerle a la ciudadanía más posibilidades de control y de participación. Es imperativo proveer a la población con la información que necesita para poder evaluar las acciones del gobierno y para participar más en los procesos políticos. Más allá de los requisitos legales se impone una nueva concepción de la rendición de cuentas que supere la información legal mínima exigida y permita a los ciudadanos realizar 
una auténtica valoración social de la actividad pública (Rivero, Mora y Flores, 2007).

La información es un bien que tiene un coste en términos de tiempo para adquirirla y en términos de formación para utilizarla adecuadamente. En muchos casos es difícil de obtener información de calidad, transparente y asequible y, por lo tanto, es necesario crear los mecanismos adecuados para facilitar la accesibilidad a la misma. En este sentido, una información transparente y simple permite entender, por ejemplo, el gasto de los recursos públicos, el destino de los impuestos de los contribuyentes en la esfera pública, o la finalidad de las cuotas de los asociados o miembros de las organizaciones y asociaciones. La información es uno de los pilares de la democracia y permite al ciudadano incorporarse más al desarrollo de la misma e implicarse en el futuro de las sociedades. Por lo tanto, es imprescindible el suministro de una información adecuada respecto a los resultados de las organizaciones en las esferas privadas y públicas.

De Piero (2005: 246) indica que la construcción de la opinión pública no debería estar atada sólo a un procedimiento de eficacia en la llegada del mensaje, sino que tendría que apuntar a un vasto debate abierto, en el cual la sociedad civil y el Estado deben participar con sus voces, las cuales se espera que se traduzcan en acciones de la administración estatal, es decir, en políticas públicas. Es preciso un diálogo crítico e interactivo, que permita construir y encontrarse con el otro, de tal forma que se establezcan espacios de vinculación pública entre ciudadanos y gobierno. La web 2.0 y las redes sociales pueden ser ese lugar de encuentro para facilitar una conversación constante que redunde en una mejor acción del gobierno y un mayor compromiso de los ciudadanos.

La potencialidad de las redes sociales (para mejorar la sociedad, hacerla más inclusiva, participativa, democrática y justa) es enorme y no puede desaprovecharse. Las administraciones y los representantes políticos deben perder el miedo y usar estas tecnologías no sólo para mejorar la información y la comunicación con los ciudadanos, sino especialmente para crear nuevos canales de deliberación y participación. Por otra parte, es necesario que el acceso y el uso de las nuevas tecnologías se conviertan en derechos de toda persona y que los gobiernos, especialmente en los Estados descentralizados, apliquen el principio de solidaridad para garantizar este derecho como un servicio público universal, accesible, de calidad y económico (Durán, 2009: 124).

\section{Las instituciones europeas en las redes sociales}

El análisis de los espacios web de las principales instituciones de la Unión Europea puede aportarnos una visión actualizada de la utilización por parte de estos organismos de las herramientas que proporciona la Web 2.0 y las redes sociales para comunicarse y conversar con los eurociudadanos.

Las instituciones elegidas fueron el Consejo Europeo, que determina la dirección y las prioridades políticas generales de la Unión Europea; el Parlamento Europeo, que representa a los ciudadanos de la UE y es elegido directamente por ellos; el Consejo de la Unión Europea, que representa a cada uno de los Estados miembros; la Comisión Europea, que defiende los intereses de la Unión en su conjunto; el Tribunal de Justicia, que vela por el cumplimiento de la legislación europea; el Tribunal de Cuentas, que controla la financiación 
de las actividades de la Unión; el Comité Económico y Social Europeo, que representa a la sociedad civil, la patronal y los asalariados; el Comité de las Regiones, que representa a las autoridades regionales y locales; el Banco Europeo de Inversiones, que financia proyectos de inversión de la UE y ayuda a las pequeñas empresas a través del Fondo Europeo de Inversiones (también analizado); el Banco Central Europeo, responsable de la política monetaria europea; el Defensor del Pueblo Europeo, que investiga las denuncias relativas a una mala gestión por parte de las instituciones y los organismos de la UE. Además de los espacios en Internet de estos organismos, se analizó "Europa: portal de la Unión Europea" y las webs de los siete grupos políticos con representación en el Parlamento Europeo ${ }^{1}$.

Los primeros datos del estudio (figura 1) muestran que las entidades y organismos de la UE ya utilizan con asiduidad las prestaciones que ofrece la Web 2.0. Por ejemplo, el 70\% cuenta con un mapa del sitio y el $90 \%$ de un buscador interno para facilitar la navegación de los internautas. Más consolidados están, si cabe, los servicios destinados a los medios de comunicación: el 95\% tienen un espacio específico para periodistas y el 100\% disponen de notas de prensa y de fotografías o vídeos para descargar.

Figura 1: Servicios web de las instituciones europeas.

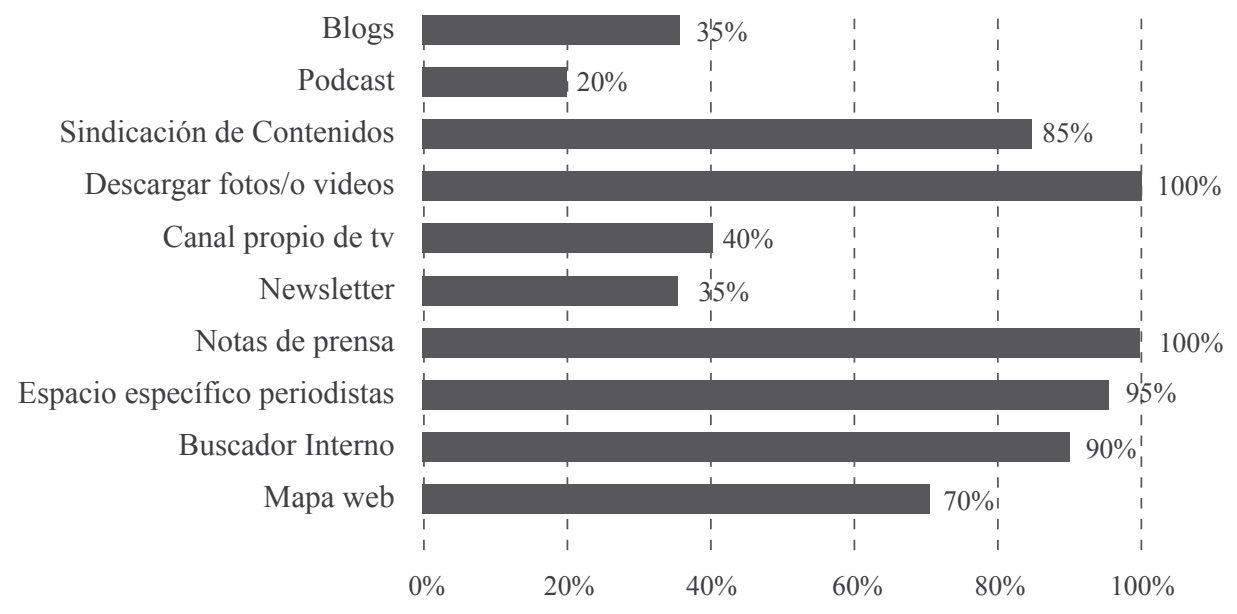

Fuente: Elaboración propia.

Hay que destacar que cerca de la mitad de las instituciones analizadas (el 40\%) disponen de un canal de televisión propio, mientras que el newsletter es un instrumento que cada vez se utiliza menos (35\%) dado que la sindicación de contenidos (ofertada por un $85 \%$ ) ofrece un servicio similar al permitir la subscripción a los nuevos contenidos de estas webs. Menos

1.- Grupo del Partido Popular Europeo (Demócrata-cristianos); Grupo de la Alianza Progresista de los Socialista y Demócratas; Grupo de la Alianza de los Demócratas y Liberales por Europa; Conservadores y Reformistas Europeos; Grupo de los Verdes / Alianza Libre Europea; Grupo Confederal de la Izquierda Unitaria Europea / Izquierda Verde Nórdica; y Europa de la Libertad y de la Democracia. 
utilizados son otros dos recursos: el podcast (20\%) y los blogs $(35 \%)$, que tuvieron un momento de auge pero están siendo sustituidos por perfiles en las distintas redes sociales.

Estos datos indican que las instituciones europeas tienen en los medios de comunicación un público prioritario, al que intentan ofrecer las mayores facilidades para que difunda entre la ciudadanía la información generada por los principales organismos y grupos políticos de la UE. A continuación, el análisis se centra en la utilización de las redes sociales (figura 2) como un instrumento para dialogar directamente con los ciudadanos.

Figura 2: Instituciones de la Unión Europa en redes sociales.

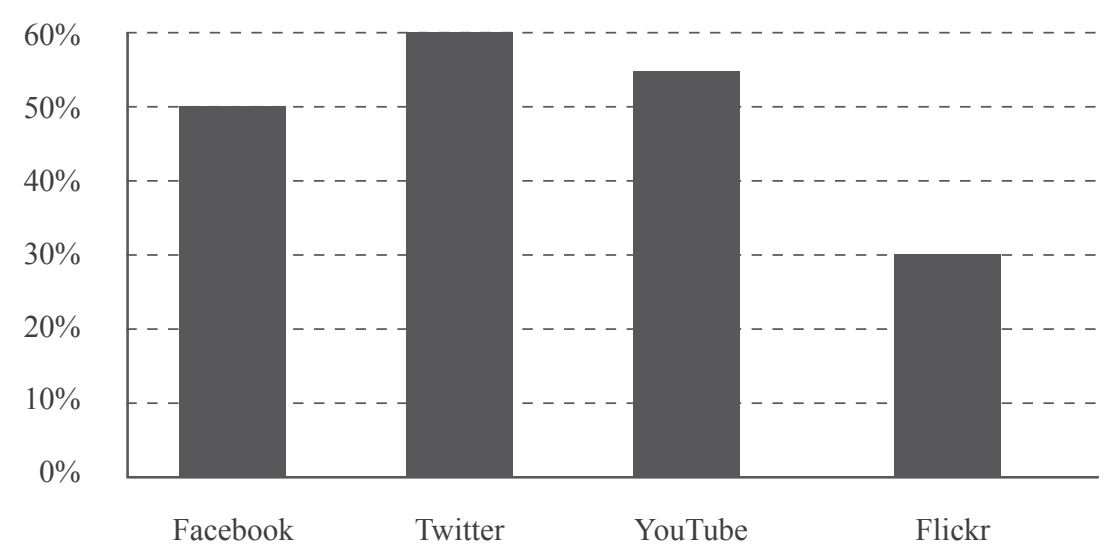

Fuente: Elaboración propia.

Los resultados indican que Twitter es la red social más extendida, con un $60 \%$ de las webs analizadas. Sin embargo, los datos de tweets (poco más de 13200 ) y seguidores (apenas 35 500) demuestran que las instituciones europeas están todavía en una fase inicial en el uso de lugar de encuentro y comunicación con los ciudadanos. En segundo lugar, aparece YouTube, ya que el 55\% de estas entidades dispone de un canal propio en este espacio de intercambio de vídeos. En tercer lugar aparece Facebook, el cual es utilizado por la mitad de las instituciones y tiene un gran potencial de crecimiento: los 25600 "amigos" que suman entre todas las webs es insignificante para un territorio que cuenta con más de 500 millones de habitantes.

Por último, Flickr, centrada en el intercambio de imágenes o fotografías, llega al 30\%. Estos datos indican que las instituciones europeas han empezado a utilizar las redes sociales pero de forma tímida e indecisa. Crear un perfil en una red social es un trámite que dura minutos pero crear una comunidad y mantenerla es un proceso mucho más lento y costoso. Aprender a relacionarse con su comunidad requiere de una apuesta mucho más decidida.

Las instituciones con mayor presencia en las redes sociales son el Parlamento Europeo, el 
Consejo Europeo, el Consejo de la Unión Europea y la Comisión Europea. El Parlamento Europeo es el único que tiene perfil en las cuatro redes analizadas y en alguna más, como Myspace. Los organismos jurídicos, económicos y consultores (Tribunal de Justicia de las Comunidades Europeas, Tribunal de Cuentas Europeo, Banco Central Europeo, Banco Europeo de Inversiones, Comité Económico y Social Europeo y Comité de Regiones) no tienen presencia en estos medios sociales, con excepción del Banco Central Europeo, el cual tiene una cuenta en Twitter y un canal en YouTube. Especialmente significativo es el caso del Defensor del Pueblo Europeo, que sólo dispone de un canal en YouTube, pero no de perfiles en Facebook o Twitter. Por el contrario, casi todos los grupos políticos participan en las cuatro redes sociales analizadas, e incluso, algunos disponen de un canal de televisión online propio. Sin embargo, las cifras de amigos y seguidores son muy bajas e indican una utilización reciente de estos medios y un escaso conocimiento y/o interés por parte de la ciudadanía europea.

Una atención especial merece "Europa: el portal de la Unión Europea”, en el que existe un apartado específico para fomentar la participación de los ciudadanos (“¡Participe!”), que incluye un subapartado para conectar con la UE a través de las redes sociales. Allí se encuentran las diversas oficinas, agencias e instituciones de la UE que han creado cuentas oficiales en redes sociales y plataformas de intercambio de contenidos. Además, acoge un enlace que permite mantenerse al día de las intervenciones en Twitter de eurodiputados, grupos políticos y comisarios a través de "Europatweets". También existe la posibilidad de utilizan los servicios de RSS y podcasts para seguir la actualidad y estar informado con las últimas noticias generadas desde el seno de la UE.

Las cifras registradas indican que la utilización de las redes sociales por parte de las instituciones europeas está en una fase embrionaria, pero es fundamental que sean utilizadas como una herramienta de Relaciones Públicas, de conversación y debate con la ciudadanía y no como un arma de propaganda.

\section{Conclusiones}

El proceso de globalización, Internet, la web 2.0 y las redes sociales son elementos que han producido numerosas transformaciones en las relaciones de los organismos con los ciudadanos. La comunicación institucional debe superar un modelo de comunicación unidireccional y lineal, para dar lugar a procesos de Relaciones Públicas basados en la retroalimentación, en la que los individuos tengan cada vez un mayor protagonismo. Para lograrlo, hay que crear contenidos de calidad y diferenciarse del resto. Ya no es suficiente con tener presencia en Internet: es preciso participar en la vida de la red. Los organismos del siglo XXI deben estar conectados, deben ser organismos en la red.

Para consolidar este tipo de comunicación relacional es básico una apuesta decidida por el "gobierno abierto", que podemos definir como el conjunto de prácticas por las que los gobiernos democráticos se relacionan con los ciudadanos, aplicando los principios de conversación permanente (feedback: escuchar y responder) para conocer sus opiniones 
y reaccionar ante las mismas, mejorándose así la prestación de servicios y la gestión del bien público. La transparencia es una necesidad, una obligación, no una alternativa. Para alcanzar este objetivo es preciso una interacción entre gobernantes y gobernados. En ese contexto, las Relaciones Públicas (a través de las redes sociales) pueden ser esa herramienta que permita esa comunicación bidireccional.

El proceso de construcción europea requiere el compromiso activo de todos los ciudadanos, pero especialmente de las generaciones que van a dirigir el futuro. Los jóvenes han dado muestra de un notable desinterés hacia las instituciones europeas que es preciso corregir, si se pretende una Unión Europea cohesionada económica, política y socialmente. Dado que estamos ante una "generación digital", habituada a utilizar todo tipo de tecnología y a un tipo de relación en la que las conversaciones se establecen en un plano de igualdad, las instituciones europeas deben adaptarse a este lenguaje y utilizar los instrumentos pertinentes.

Los espacios en la Internet de los principales organismos y partidos políticos de la UE utilizan gran parte de las herramientas que pone a su disposición la Web 2.0. Sin embargo, todavía están prioritariamente orientadas a satisfacer las necesidades de información de los medios de comunicación, que son concebidos como el intermediario natural para hacer llegar los mensajes a la opinión pública. Así, el 95\% dispone de un espacio específico para periodistas y todas ofrecen notas de prensa, imágenes o vídeos para descargar. Sin embargo, ha llegado el momento de dar un paso más e iniciar una conversación directa con la ciudadanía de los distintos países.

Las redes sociales permiten una plasmación efectiva del modelo "simétrico bidireccional" de las Relaciones Públicas, ya que se han convertido en un escenario donde se puede lograr una comunicación fluida y una relación directa (face to face) entre los organismos comunitarios y los nuevos ciudadanos europeos. Son un espacio idóneo de conversación y debate que puede contribuir al proceso de identidad europea. Para ello, las instituciones de la UE deben escuchar, tener empatía, contestar, crear contenidos interesantes, valorar las aportaciones de los individuos, ser coherentes, adaptarse a los cambios y, sobre todo, hablar "horizontalmente". Lo que los jóvenes y los ciudadanos exigen es más transparencia, más honestidad, participación, proximidad y autenticidad.

Twitter es la red social más utilizada por las instituciones europeas, puesto que el $60 \%$ de estas entidades disponen de un perfil en esta red de microblogging. A continuación, aparecen YouTube (55\%), Facebook (50\%) y Flickr (30\%). Lo importante no es lograr tener followers o "seguidores", sino escuchar y conversar con los ciudadanos. Cuando una institución decide utilizar una de estas herramientas y crearse un perfil en las distintas redes sociales existentes, debe ser consciente de las obligaciones que tiene con la ciudadanía a través de la misma y que con ello adquiere una serie de compromisos que no debe traicionar.

El uso de las redes sociales genera confianza. Las instituciones europeas deben aprender a usarlas, ya que todavía no se atreven a utilizarlas para establecer un diálogo fluido con los ciudadanos. Tienen que tejer redes y cuidar de ellas. Las redes sociales permiten una transformación revolucionaria del espacio político tradicional, antes ordenado y jerarquizado. Los políticos tienen miedo porque no controlan el medio, pero el control ya ha dejado de ser relevante: lo importante es la conversación. La revolución ya está entre 
nosotros, pero las instituciones europeas apenas han empezado a darse cuenta.

El nuevo modelo de sociedad brinda protagonismo al individuo. El ciudadano debe ser el centro de la nueva sociedad hiperconectada. Las redes sociales son una posibilidad de cercanía, de proximidad, de contacto directo. Suponen una gran oportunidad en el proceso de construcción de la ciudadanía europea, que será una ciudadanía más participativa (activa), más conectada y en constante conversación. Las instituciones europeas deben participar de una forma más decidida en las redes sociales y dialogar "de igual a igual" con este nuevo ciudadano crítico, capaz de pensar, de decidir y de asumir responsabilidades para la construcción conjunta de la Unión Europea.

\section{Fuentes consultadas}

Almansa, A. (2004). Teoría, estructura y funcionamiento de los gabinetes de comunicación. El caso andaluz. Málaga: Universidad de Málaga.

Bouza, F. (2006). "La influencia de los medios en la formación de la opinión pública: los procesos jurídicos y los juicios paralelos”. En Doxa Comunicación, núm. 5, 15-32.

Cabezuelo, F. (2005). "Autocrítica de los profesionales de la información y la comunicación en el proceso de construcción europea”, pp. 207-224. En Información para la Paz: autocrítica de los medios y responsabilidad del público. Valencia: Fundación COSO.

Calderón, C. y Lorenzo, S. (2011). Open Government. Gobierno abierto. Jaén: Algón Editores.

Castillo, A. (2010). Introducción a las Relaciones Públicas. Málaga: Instituto de Investigación en Relaciones Públicas.

Castillo, A. y Almansa, A. (2008). "Estudio sobre el uso de las nuevas tecnologías en la comunicación institucional”. Icono 14, núm. 11.

De Piero, S. (2005). Organizaciones de la sociedad civil: tensiones de una agenda en construcción. Buenos Aires: Paidós.

Durán Ruiz, F. J. (2009). "Retos y oportunidades de la administración y el gobierno electrónicos: Derecho a las TIC y alfabetización digital". Zona Próxima, Revista del Instituto de Estudios en Educación de la Universidad del Norte, núm. 10, 104-125.

Galindo, F.

_(2008). Sobre la percepción periodística. Delimitación conceptual y aplicaciones metodológicas. Actas del Primer Congreso AE-IC “Investigar la Comunicación”. Santiago de Compostela, España.

(1997). Las redes: nuevas ventanas a la Comunicación Política. Actas del III Congreso AECPA. Gobernabilidad y representación en las democracias. Salamanca, España.

Grasa Hernández, R. (2005). "Instituciones para una cooperación al desarrollo de calidad”. Revista Cidob d'Afers Internacionals, núm. 72, pp. 85-95.

Grunig, J. E. y Hunt, T. (2000). Dirección de Relaciones Públicas. Barcelona: Gestión 2000. 
Innerarity, D.

_(2006). El nuevo espacio público. Madrid: Espasa Calpe.

_(2004). La sociedad invisible. Madrid: Espasa Calpe.

León y Ramírez, J. C. (2009). “La dimensión pública del buen gobierno: la administración ciudadana del quehacer colectivo". Convergencia, 49(16), 277-289.

Losada Díaz, J. C. (coord.) (2004). Gestión de la comunicación en las organizaciones. Barcelona: Ariel.

Manfredi Sánchez, J. L. (2010). "Periodismo y transparencia informativa". En Cuadernos de Periodistas, núm. 19, 113-123.

Martínez, Y. (2004). La comunicación institucional. Análisis de sus problemas y soluciones. Madrid: Fragua.

Miguel de Bustos, J. C. (2000). "Industrias culturales, gratuidad y precios en Internet". En ZER, Revista de estudios de comunicación, núm. 9, 115-150.

Noguero, A. (1995). La función social de las relaciones públicas: historia, teoría y marco legal. Barcelona: EUB.

Nonel, R. (2002). Transparencia y buen gobierno. La rendición de cuentas en una sociedad avanzada. Barcelona: Icaria Editorial.

Obama, B. (2011). "Transparency and Open Government. Memorandum for the Heads of Executive Departments and Agencies”. Extraída el 14/IX/2011 desde http://www.whitehouse.gov/the_press_ office/TransparencyandOpenGovernment/

Pereda, C. (2011, Julio 6). "Twitter entrevista a Obama. El presidente de Estados Unidos responde desde la Casa Blanca a las preguntas enviadas por los usuarios en la red social". Extraída el 14/IX/2011 desde http://www.elpais.com/articulo/internacional/Twitter/entrevista/Obama/ elpepuint/20110706elpepuint_6/Tes

Rivero Méndez, J. A.; Mora Agudo, L. y Flores Ureba, S. (2007). Un estudio de la rendición de cuentas a través del e-gobierno en la administración local española. XXI Congreso Anual AEDEM, Universidad Rey Juan Carlos. Junio 6-8, Madrid.

Rubio, R. (2010). "Nuevas tecnologías y transparencia parlamentaria”. En Cuadernos Evoca, núm. 4, 22-27.

Schedler, A. (2004). “¿Qué es la rendición de cuentas?”. Extraída el 25/III/2011 desde http://www. programaanticorrupcion.gob.mex/rend

Solano, L. (1999). Tratado de Relaciones Públicas. Barcelona: Gestión 2000.

Werner, A. F. (2008). "Transparencia y el gobierno electrónico. Dos herramientas del buen gobierno en el proceso de democratización”. Razón y Palabra, núm. 61.

Xifra, J. (2008). "Modelos de las relaciones públicas políticas: Análisis de la situación en Cataluña". Revista Latina de Comunicación Social, núm. 63, 392-399.

Wolf, M. (1991). Teorie delle comunicazione di massa. Buenos Aires: Paidós. 